\title{
Application of Hanseniaspora vineae Yeast in the Production of Rosé Wines from a Blend of Tempranillo and Albillo Grapes
}

\author{
Juan Manuel Del Fresno ${ }^{1}$, Iris Loira ${ }^{1}$, Carlos Escott ${ }^{1}$, Francisco Carrau ${ }^{2}$, Carmen González ${ }^{1}$, Rafael Cuerda ${ }^{3}$ and \\ Antonio Morata ${ }^{1, *}$ \\ 1 enotecUPM, Chemistry and Food Technology Department, Escuela Técnica Superior de Ingeniería \\ Agronómica, Alimentaria y de Biosistemas, Universidad Politécnica de Madrid, Avenida Complutense S/N, \\ 28040 Madrid, Spain; juanmanuel.delfresno@upm.es (J.M.D.F.); iris.loira@upm.es (I.L.); \\ carlos.escott@gmail.com (C.E.); carmen.gchamorro@upm.es (C.G.) \\ 2 Área Enología y Biotecnología de Fermentaciones, Facultad de Química, Universidad de la Republica, \\ Gral. Flores 2124, Montevideo 11800, Uruguay; fcarrau@fq.edu.uy \\ 3 Comenge Bodegas y Viñedos SA, Curiel de Duero, 47316 Valladolid, Spain; cuerda@comenge.com \\ * Correspondence: antonio.morata@upm.es
}

check for updates

Citation: Fresno, J.M.D.; Loira, I.; Escott, C.; Carrau, F.; González, C.; Cuerda, R.; Morata, A. Application of Hanseniaspora vineae Yeast in the Production of Rosé Wines from a Blend of Tempranillo and Albillo Grapes. Fermentation 2021, 7, 141. https://doi.org/10.3390/

fermentation7030141

Academic Editor: Rosanna Tofalo

Received: 13 July 2021

Accepted: 30 July 2021

Published: 3 August 2021

Publisher's Note: MDPI stays neutral with regard to jurisdictional claims in published maps and institutional affiliations.

Copyright: (c) 2021 by the authors. Licensee MDPI, Basel, Switzerland. This article is an open access article distributed under the terms and conditions of the Creative Commons Attribution (CC BY) license (https:/ / creativecommons.org/licenses/by/ $4.0 /)$.

\begin{abstract}
Hanseniaspora vineae is an apiculate yeast that can be used for the production of interesting commercial wines, due to its contribution of fermentative volatiles. This paper presents a detailed comparative study of the use of H. vineae, compared to pure fermentations of S. cerevisiae in Tempranillo and Albillo rosé wines. Fermentations were carried out in oak barrels and stainless steel barrels. The results indicated that fermentation with $H$. vineae resulted in wines with residual sugars below $3.4 \mathrm{~g} / \mathrm{L}$ and similar general characteristics, compared to $S$. cerevisiae. However, $H$. vineae wines contain up to $44 \%$ more total anthocyanins, resulting in an appreciable improvement in colour. In addition, $H$. vineae produced up to $65 \%$ more 2-phenylethyl acetate in stainless steel barrels and 2.5 times more terpene alcohols in oak barrels. Therefore, the use of $H$. vineae results in a more attractive colour, as well as fruity and floral organoleptic characteristics of rosé wines.
\end{abstract}

Keywords: Hanseniaspora vineae; alcoholic fermentation; non-Saccharomyces; rosé wines; polysaccharides; colour parameters; anthocyanins; polysaccharides; volatile compounds

\section{Introduction}

Rosé wines are made from red grape varieties, in order to extract the amount of pigments that give them their characteristic colour. However, these wines are very similar to white wines, both in terms of the technology used, which consists of separating the must by a rapid bleeding or pressing directly on the grapes [1]; and in terms of their sensory characteristics, as white and rosé wines are usually consumed young with floral and fruity sensory characteristics. Rosé wines are difficult to make, as short macerations lead not only to a low extraction of anthocyanins but also to a poor extraction of volatile compounds from the skins; therefore, the generation of volatile compounds during fermentation plays an important role in the production of quality rosé wines [2]. Rosé wines are mainly a type of fresh wine, and in this respect the use of non-Saccharomyces yeasts is an important tool to obtain fresh wines of differentiated quality [3]. Yeasts live on the surface of the grape skins, and the population varies constantly due to climatic conditions and the ripening stage of the berry. At harvest time there is a complex yeast population where S. cerevisiae is not the most abundant [4]. For this reason, non-Saccharomyces yeasts are dominant at the beginning of alcoholic fermentation, and play an important role in the organoleptic complexity of the wine obtained. The main non-Saccharomyces yeasts associated with grapes are the genus Hanseniaspora and its asexual anamorph Kloeckera, these yeasts are apiculate with bipolar budding [5]. These apiculate yeasts are normally characterised by their low fermentation capacity compared to $S$. cerevisiae, as these species generally do 
not tolerate ethanol concentrations higher than $5-7 \%$ vol [6], however $H$. vineae strains are capable of producing in up to a $9 \%$ ethanol volume [7].

The choice of $H$. vineae as a yeast in rosé winemaking is not limited to its adequate fermentative capacity. Different authors have investigated its application in white winemaking conditions and achieved interesting results. Medina et al., 2013 [7] used a selected strain of $H$. vineae for the production of high quality Chardonnay white wines, fermented in oak barrels. These wines showed a fruity and intense flavour character, with an increased full body and a relatively long palate length, compared to pure $S$. cerevisiae treatments. In addition, other authors have obtained significant organoleptic improvements when using $H$. vineae, based mainly on the production of certain volatile compounds during alcoholic fermentation. In particular, several authors have reported the increase in fruity aromas, due to the high production of 2-phenylethyl acetate and ethyl acetate [8]. 2-Phenylethyl acetate is an acetic ester that gives wines fruity and floral aromas with honey notes [9]. This compound has an important aromatic repercussion, with a $0.25 \mathrm{mg} / \mathrm{L}$ of odour threshold [10]. The esters in wines are formed as a consequence of the amino acid catabolism by the Ehrlich transamination pathway, and the higher alcohol formed in this process can be esterified with acetic acid. In addition, $H$. vineae can produce 2-phenylethyl acetate from sugars, following the chorismate-prephenate-(S)-mandelate/phenylalanine pathway [3]. In fact, [11] identified up to 50 times more concentration of 2-phenylethyl acetate in $H$. vineae wines than in S. cerevisiae wines in Macabeo white must fermentation. We have also obtained similar results in white winemaking of the Albillo grape must, with significant higher concentrations of 2-phenylethyl acetate compared to S. cerevisiae wines [12]. Another important characteristic of $H$. vineae is the synthesis and glucosidase and the capacity that it has for increasing free terpenes and sesquiterpenes compounds after fermentation [5]. In this respect, in previous studies we identified a significant effect of this yeast on terpene contents, where we obtained up to three times higher contents of linalool, $\beta$-citronellol, geraniol and $\alpha$-terpineol compared to $S$. cerevisiae fermentations [13].

The aim of this work is to study the application of $H$. vineae yeast for the production of rosé wines from Tempranillo and Albillo grape varieties. Tempranillo is the dominant variety in Ribera del Duero (Spain), and accounts for 95\% of the surface area [14]. This variety produces red wines with a strong violet colour, medium acidity and well-structured tannin. Aromas of blackberry and black forest fruits are typical of wines made from Tempranillo grapes [15]. The main white grape variety in this D.O. is Albillo Mayor. This variety is well adapted to this area and ripens early, producing wines with medium acidity and aromas of pome and stone fruits, apple and peach [15]. The production of rosé wines from the blend of these two grape varieties is a practice of growing interest in this D.O. It is therefore interesting to evaluate the application of yeasts that improve the aromatic profile of this type of wine. Similarly, winery scale studies provide more realistic information on the potential industrial application of the yeast under study. Information about the characteristics of the wines fermented in oak barrels is also interesting because it is a common method in the production of high-quality wines. For this purpose, pure fermentations have been carried out using $H$. vineae or S. cerevisiae fermentations at a winery scale. All fermentations have been carried out in both stainless steel and oak barrels. Final wines have been analysed in order to obtain different data of importance on the quality of rosé wines. Analyses carried out were as follows: ethanol, $\mathrm{pH}$, glucose-fructose, volatile acidity, colour parameters, anthocyanins profile, polysaccharide content, volatile compounds and sensory analysis.

\section{Materials and Methods}

\subsection{Yeast Strains Used in Fermentation of Rosé Wines}

The yeast strain T02/5A H. vineae was used for the fermentation of Tempranillo and Albillo must. This yeast strain is currently under evaluation by "Oenobrands SAS, France", and it was isolated by Francisco Carrau (Facultad de Química, Universidad de la República, 
Montevideo, Uruguay). H. vineae was inoculated at a population of $7 \log \mathrm{CFU} / \mathrm{mL}$ after being grown in YPD medium.

The yeast strain Fermivin 3C (S. cerevisiae), used as a conventional control in this study, is a selected commercial yeast (Oenobrands SAS, Montpellier, France). S. cerevisiae was inoculated as active dried yeast after hydration, according to the manufacturer's instructions at a dosage of $20 \mathrm{~g} / \mathrm{hL}$.

\subsection{Must and Fermentation Conditions}

The rosé must was obtained by direct pressing of a mixture of $50 \%$ Tempranillo and $50 \%$ Albillo grapes from the Ribera de Duero region in Spain. Only at this stage of the production process was the liquid in contact with the skins, so there was no maceration prior to the fermentation process. This must showed the following characteristics before inoculation with the two yeast species studied: $1093 \mathrm{~g} / \mathrm{L}$ of density; $\mathrm{pH}=3.34 ; 4.05 \mathrm{~g} / \mathrm{L}$ of total acidity expressed as tartaric acid and $15.05 \mathrm{mg} / \mathrm{L}$ of total $\mathrm{SO}_{2}$ content.

The fermentations with $H$. vineae were carried out in stainless steel barrels with $150 \mathrm{~L}$ capacity in triplicate (HV), and in oak barrels with $225 \mathrm{~L}$ capacity in duplicate (HVW). The $H$. vineae yeast strain that was used can ferment until $9 \%$ vol of ethanol content. The end of the fermentation process was likely carried out by a S. cerevisiae yeast strain, possibly from the winery population or from the grape skin population.

The S. cerevisiae fermentations were carried out in the same way (SC and SCW). All fermentations were carried out in "Bodegas Comenge" (Curiel de Duero, Valladolid, Spain), in a room at a controlled temperature $\left(18^{\circ} \mathrm{C}\right)$. The fermentation process was controlled by density measurement. Population monitoring of both yeast species was carried out by periodic sampling and microscopic observation.

\subsection{General Oenological Parameters Analyses}

Ethanol $(\% v / v)$, volatile acidity $(\mathrm{g} / \mathrm{L})$ expressed as acetic acid and glucose/fructose content $(\mathrm{g} / \mathrm{L})$ were analysed using an OenoFoss instrument (FOSS Iberia, Barcelona, Spain). This instrument provides a great number of oenological parameters by Fourier transform infrared spectroscopy (FTIR).

\subsection{Colour Parameters Analyses}

A Smart Analysis (DNA Phone s.r.l, Parma, Italy) spectrophotometer was used to measure the colour parameters with a $1 \mathrm{~mm}$ plastic cuvette. This instrument allows the direct measurement of absorbance at 420,520 and $620 \mathrm{~nm}$, the parameters colour intensity, tonality and CIELab coordinates.

\subsection{Anthocyanins Analysis}

Pigment content was determined by HPLC-DAD according to [16]. The equipment used was an Agilent Technologies (Palo Alto, CA, USA) series 1100 HPLC chromatograph, equipped with a diode array detector and a quadrupole mass spectrometer with an electrospray interface and a column RP Kinetex C18 100 Â $(100 \times 4.6 \mathrm{~mm} ; 2.6 \mu \mathrm{m})($ Phenomenex, Torrance, CA, USA). The solvents were: Solvent A (water/formic acid 95:5 $v / v$ ) and Solvent B (methanol/formic acid 95:5 $v / v$ ).

\subsection{Polysaccharide Analysis}

The polysaccharide analysis was carried out according to the method described by [17]. The technique used for the analysis was HPLC-RI by means of an 1100 HPLC chromatograph (Agilent Technologies, Palo Alto, CA, USA), equipped with a refractive index detector with Ultrahydrogel 250 molecular exclusion column (Waters).

The following standards of pullulan (polymaltotriose) (Shodex, Showa Denko K.K, Tokyo, Japan) were used for the calibration curve: P-800 (788 kDa), P-400 (404 kDa), P200 (212 kDa), P-100 (112 kDa), P-50 (47.3 kDa), P-20 (22.8 kDa), P-10 (11.8 kDa) and P-5 
(5.9 kDa). The eluent used for this method was $0.1 \mathrm{M} \mathrm{NaNO}_{3}$ in deionised water (MilliQ, Merck KGaA, Darmstadt, Germany).

\subsection{Fermentation Volatile Compounds Analysis}

The analysis of volatile compounds of fermentative origin were analysed according to the method described by [18]. The measurement was carried out using an Agilent Technologies 6850 gas chromatograph, equipped with an integrated flame ionisation detector (GC-FID) and DB-624 column $(60 \mathrm{~m} \times 250 \mu \mathrm{m} \times 1.40 \mu \mathrm{m})$. The detector temperature was $300{ }^{\circ} \mathrm{C}$, and the injector temperature was $250{ }^{\circ} \mathrm{C}$. The carrier gas was hydrogen. External standards were used for the calibration of the method.

\subsection{GC-MS Analysis}

Terpene alcohols and volatile compounds from wood were measured only in oak barrel fermented wines by gas chromatography - mass spectrometer (GC-MS). The equipment used was an Agilent Technologies 6890N-MSD-5973N gas chromatography-mass spectrometer. The column used to perform the chromatographic separation was a DB-WAX column ( $30 \mathrm{~m} \times 0.25 \mathrm{~mm}$ internal diameter $\times 0.25 \mu \mathrm{m}$ film thickness) (J\&W Scientific, Folsom, CA, USA).

Prior to injection into the equipment, an extraction with dichloromethane was carried out. A $2.5 \mathrm{~mL}$ volume of rosé wine was mixed with $250 \mu \mathrm{L}$ of dichloromethane and $25 \mu \mathrm{L}$ of 3.4-dimethylphenol solution (10 mg/L) (Merck, Hohenbrunn, Germany) as the internal standard; $0.37 \mathrm{~g}$ of $\mathrm{NaCl}$ was added and stirred in a vortex for $5 \mathrm{~min}$. After centrifugation at $7500 \mathrm{rpm}$ for $15 \mathrm{~min}$ at $4{ }^{\circ} \mathrm{C}, 1 \mu \mathrm{L}$ of the dichloromethane phase was injected into the chromatograph. The following external standards were used for the calibration of the method: furfural, linalool, 5-methyl furfural, furfuryl alcohol, $\alpha$-terpineol, guaiacol, cis-oak lactone, $\beta$-ionone, trans-oak lactone, eugenol and 4-ethylphenol.

\subsection{Sensory Analysis}

All sensory analysis parameters were rated on a scale from 1 (low perception) to 5 (high perception), except for the tonality parameter which was evaluated from 1 (purple tones) to 5 (yellow tones). The parameters assessed were colour intensity, tonality, aromatic intensity, aromatic quality, floral, fruity, wood, yeasty aroma, sweetness, bitterness, acidity and freshness. The global impression was also evaluated. The assessments were made by an expert panel of seven judges of both genders, with ages from 27 to 50 years old. The panel was constituted of members of the Chemistry and Food Technology Department of Escuela Técnica Superior de Ingenería Agronómica, Alimentaria y de Biosistemas (UPM, Madrid, Spain).

\subsection{Statistical Analysis}

Means, standard deviations, analysis of variance and the least significant difference test $(p<0.05)$ were calculated using PC Statgraphics v.5 software (Graphics Software Systems, Rockville, MD, USA).

\section{Results and Discussion}

\subsection{General Oenological Parameters Obtained after the Alcoholic Fermentation}

The general oenological parameters are shown in Table 1 . The ethanol content was between $12.7 \%$ and $13.27 \%$ vol in all wines studied, without significant differences for the yeast strain used. In the same way, the material of the stainless steel did not have an effect on the ethanol content. Some differences were found regarding the $\mathrm{pH}^{\prime} \mathrm{s}$ values, as the wines fermented in oak barrels showed lower $\mathrm{pH}$ values. 
Table 1. General oenological parameters in rosé wines measured by FTIR.

\begin{tabular}{ccccc}
\hline $\begin{array}{c}\text { Rosé } \\
\text { Wines }\end{array}$ & Ethanol $(\%$ v/v) & $\mathbf{p H}$ & $\begin{array}{c}\text { Glucose-Fructose } \\
(\mathrm{g} / \mathrm{L})\end{array}$ & $\begin{array}{c}\text { Volatile Acidity } \\
(\mathrm{g} / \mathrm{L} \text { Acetic Acid) }\end{array}$ \\
\hline SC & $12.90 \pm 0.53^{\mathrm{a}, \mathrm{b}}$ & $3.51 \pm 0.03^{\mathrm{c}}$ & $3.45 \pm 0.45^{\mathrm{a}}$ & $0.44 \pm 0.11^{\mathrm{a}, \mathrm{b}}$ \\
HV & $12.70 \pm 0.10^{\mathrm{a}}$ & $3.43 \pm 0.04^{\mathrm{b}}$ & $2.95 \pm 1.75^{\mathrm{a}}$ & $0.42 \pm 0.01^{\mathrm{a}, \mathrm{b}}$ \\
SCW & $13.27 \pm 0.12^{\mathrm{b}}$ & $3.39 \pm 0.03^{\mathrm{a}, \mathrm{b}}$ & $2.10 \pm 0.10^{\mathrm{a}}$ & $0.52 \pm 0.02^{\mathrm{b}}$ \\
HVW & $13.20 \pm 0.10^{\mathrm{a}, \mathrm{b}}$ & $3.36 \pm 0.02^{\mathrm{a}}$ & $3.35 \pm 0.15^{\mathrm{a}}$ & $0.40 \pm 0.01^{\mathrm{a}}$ \\
\hline
\end{tabular}

SC (fermentations with S. cerevisiae in stainless steel barrels); HV (fermentations with H. vineae in stainless steel barrels); SCW (fermentations with S. cerevisiae in oak barrels); HVW (fermentations with $H$. vineae in oak barrels). Values in the same column with the same letter are not significantly different $(p<0.05)$.

All of the wines completed the fermentation process with a residual sugar content below $4 \mathrm{~g} / \mathrm{L}$, similar to typical dry wines [19] without significant differences among them (Appendix A). In all of the wines the volatile acidity was well below $0.7 \mathrm{~g} / \mathrm{L}$, considered as the sensory limit, above which it could be perceived as a wine odour defect. Only significant differences were identified between the wines produced in oak barrels, as an increase of more than $0.1 \mathrm{~g} / \mathrm{L}$ was obtained in the SCW treatments compared to the HVW wines. These low volatile acidity values in $H$. vineae wines are interesting because other authors have reported an increase in this parameter after the use of other Hanseniaspora/Kloeckera yeast species [20-22].

\subsection{Colour Parameters}

Figure 1a shows the different spectrophotometric parameters measured in the different rosé wines treatments. Colour intensity is the sum of the absorbance at 420,520 and $620 \mathrm{~nm}$. For this chromatic parameter, no significant differences were observed between the two yeast strains, but an increase in colour intensity was identified in oak barrel wines. Regarding the tonality parameter, significant differences were identified that can be seen visually (Figure $1 b$ ). S. cerevisiae wines showed a higher tonality compared to $H$. vineae wines, both in stainless steel and oak barrel fermentations, although all of the samples showed a low tonality between $0.76-0.82$. These are considered standard values in young rosé wines. These differences identified in the tonality parameter could be due to the formation of more orange pigments, such as vitisins, when fermenting with S. cerevisiae. Similarly, the production of bluer pigments during the fermentation by $\mathrm{H}$. vineae could also modify the tonality parameter, and this might be the case for the formation of acylated anthocyanins.

In an attempt to obtain more exact colorimetric results, the CIELab coordinates were used. The CIELab is a uniform three dimensional space, defined by colorimetric coordinates $\mathrm{L}^{*}, \mathrm{a}^{*}$ and $\mathrm{b}^{*}$ [23]. In Figure $1 \mathrm{c}$, a graphic representation of these coordinates can be observed. $\mathrm{L}^{*}$ is a measure of lightness, from completely opaque (0) to completely transparent (100). The bar in Figure 1c shows the representation of this parameter, and two groups of samples can be clearly identified. In addition, these two groups are statistically different. The samples fermented in stainless steel barrels showed higher $L^{*}$ values (around 85), while SCW and HVW wines resulted in lower values (around 80). It is possible that the extraction of certain compounds from the barrel by the wine modifies the lightness of it. Therefore, the yeast strain used did not influence the $L^{*}$ value.

In the hue circle in Figure $1 \mathrm{c}, \mathrm{a}^{*}$ is a measure of redness (or $-\mathrm{a}^{*}$ of greenness) and $\mathrm{b}^{*}$ of yellowness (or $-b^{*}$ of blueness). In general, all samples are grouped in the same area of the graphic representation. Coordinate $\mathrm{a}^{*}$ values were between 17.18 and 19.48, the wines SCW and HVW presented higher values, but without significant differences with SC and $\mathrm{HV}$ wines. Therefore, the yeast strain used and the material of the fermentation tank have not influenced the $\mathrm{a}^{*}$ coordinate value. In relation to the $\mathrm{b}^{*}$ coordinate, the yeast strain used had a notable influence. Wines fermented by $S$. cerevisiae resulted in statistically higher values than $H$. vineae, thus, $S$. cerevisiae wines had more yellowness, corresponding to the tonality values obtained. 
a

\begin{tabular}{cccccccc}
\hline $\begin{array}{c}\text { Rosé } \\
\text { wines }\end{array}$ & $\begin{array}{c}\text { Colour intensity } \\
\text { (absorbance } \\
\text { units) }\end{array}$ & $\begin{array}{c}\text { Tonality } \\
\text { (adimensional) }\end{array}$ & Chroma & Hue $\left(^{\circ}\right)$ & L & a & b \\
\hline SC & $0.59 \pm 0.02^{\mathrm{a}}$ & $0.82 \pm 0.01^{\mathrm{b}}$ & $21.22 \pm 0.90^{\mathrm{ab}}$ & $32.09 \pm 0.99^{\mathrm{b}}$ & $85.33 \pm 0.81^{\mathrm{b}}$ & $17.95 \pm 0.56^{\mathrm{a}}$ & $11.30 \pm 0.81^{\mathrm{b}}$ \\
HV & $0.59 \pm 0.01^{\mathrm{a}}$ & $0.80 \pm 0.02^{\mathrm{ab}}$ & $19.22 \pm 2.27^{\mathrm{a}}$ & $26.36 \pm 1.51^{\mathrm{a}}$ & $84.73 \pm 0.23^{\mathrm{b}}$ & $17.18 \pm 1.82^{\mathrm{a}}$ & $8.60 \pm 1.45^{\mathrm{a}}$ \\
SCW & $0.78 \pm 0.02^{\mathrm{b}}$ & $0.82 \pm 0.01^{\mathrm{b}}$ & $22.67 \pm 0.51^{\mathrm{b}}$ & $32.66 \pm 0.00^{\mathrm{b}}$ & $80.50 \pm 0.71^{\mathrm{a}}$ & $19.09 \pm 0.48^{\mathrm{a}}$ & $12.23 \pm 0.20^{\mathrm{b}}$ \\
HVW & $0.75 \pm 0.00^{\mathrm{b}}$ & $0.76 \pm 0.02^{\mathrm{a}}$ & $21.41 \pm 0.17^{\mathrm{ab}}$ & $24.64 \pm 0.81^{\mathrm{a}}$ & $80.50 \pm 0.00^{\mathrm{a}}$ & $19.48 \pm 0.28^{\mathrm{a}}$ & $8.88 \pm 0.23^{\mathrm{a}}$ \\
\hline
\end{tabular}
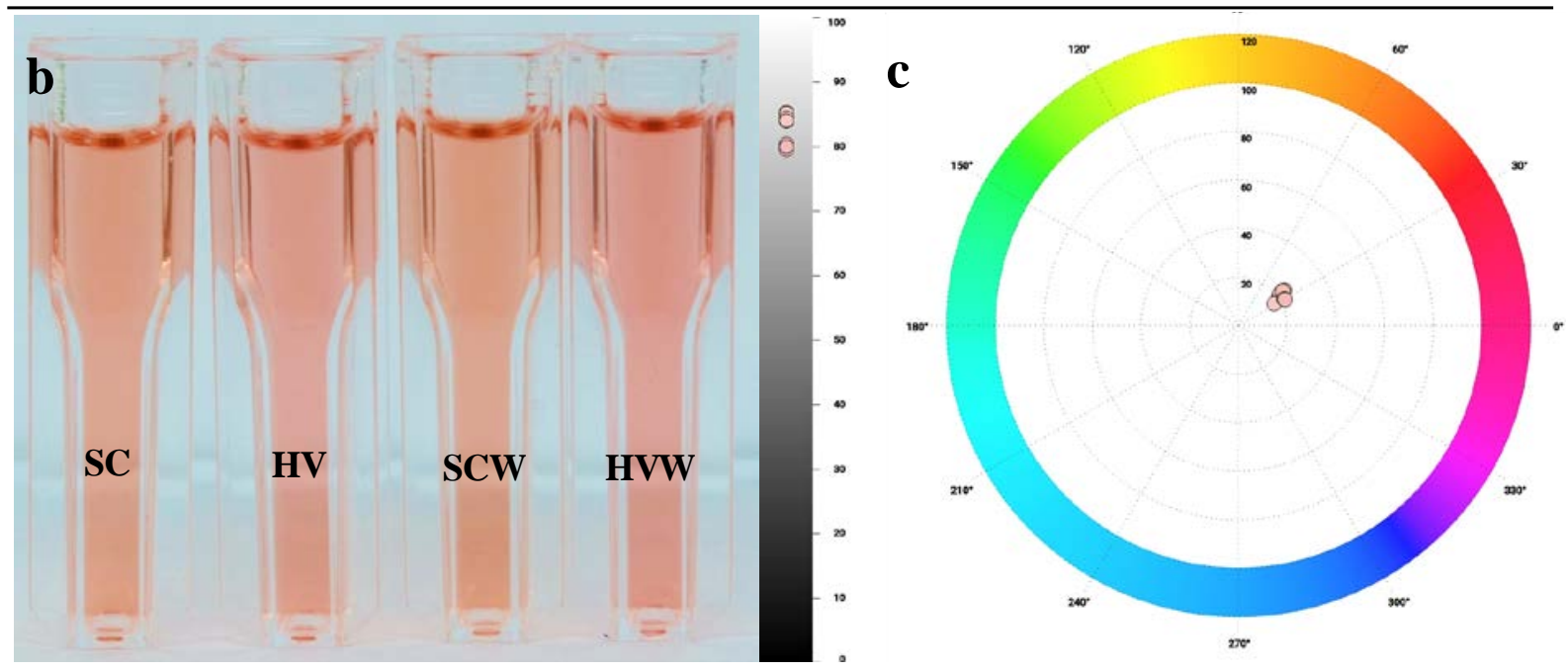

Figure 1. Colour parameter values and CIELab coordinates (a); visual colour aspect of rosé wines (b); graphic presentation of CIELab coordinates (c). SC (fermentations with S. cerevisiae in stainless steel barrels); HV (fermentations with $H$. vineae in stainless steel barrels); SCW (fermentations with S. cerevisiae in oak barrels); HVW (fermentations with H. vineae in oak barrels). Values in the same column with the same letter are not significantly different $(p<0.05)$.

Hue angle $\left(\mathrm{H}^{*}\right)$ and chroma $\left(\mathrm{C}^{*}\right)$ values are obtained from $\mathrm{L}^{*}, \mathrm{a}^{*}$ and $\mathrm{b}^{*}$ coordinates [24]. Changes in $\mathrm{C}^{*}$ in red wine reflect a bias towards the dominant colour component $\left(\mathrm{a}^{*}\right.$ or $\left.b^{*}\right)$ [25]. In all wines studied, $\left(C^{*}\right)$ values varied between 19.22 and 21.41. These values are under 50 , therefore it is expected that these wines do not show vivid colours. In the same way, $\mathrm{C}^{*}$ value was not related to the yeast strain or the tank material used. Hue angle $\left(\mathrm{h}^{*}\right)$ is defined in relation to the $+\mathrm{a}^{*}$ axis and is expressed in degrees; $0^{\circ}$ would be $+\mathrm{a}^{*}$ (red), $90^{\circ}$ would be $+\mathrm{b}^{*}$ (yellow), $180^{\circ}$ would be $-\mathrm{a}^{*}$ (green) and $270^{\circ}$ would be $-\mathrm{b}^{*}$ (blue) [26]. In Figure $1 c$, it can be seen that all wine samples are grouped between $24^{\circ}$ and $60^{\circ}$, but wines fermented by S. cerevisiae resulted in higher values of $h^{*}$. In light of this, we can conclude that the use of $H$. vineae results in wines with a tone closer to red, while fermentations with S. cerevisiae result in a more yellow tone. Therefore, it seems that the use of different yeast species for the fermentation process leads to the formation of pigments, with absorbances at different wavelengths.

\subsection{Anthocyanins}

The anthocyanins are the main agents responsible for the colour of red wines. They are made up of a monoglucosides anthocyanin (malvidin, delphinidin, peonidin, petunidin or cyanidin), substituted at position three by a molecule of glucose. The glucosides, in turn, can be acylated at position six of the sugar, with either acetic, $p$-coumaric or caffeic acid [27]. Figure 2 shows the comparison of chromatograms for the different wines studied, measured by HPLC-DAD where seven different pigments can be observed. Considering the total content of anthocyanins identified, it can be observed that wines fermented by $H$. vineae showed statistically higher contents of pigments than the wines fermented by S. cerevisiae. This increase was intensified when wines were fermented in oak barrels, obtaining up to a $44 \%$ increase in total anthocyanins in HVW samples compared to SCW samples (Table 2). It 
is interesting to note that these pigments only come from the Tempranillo red grape variety, and values around $50 \mathrm{mg} / \mathrm{L}$ have been identified by other authors when making rosé wines from Cabernet Sauvignon grapes [28]. Other authors have obtained lower amounts of total pigments, around $22 \mathrm{mg} / \mathrm{L}$ [29]. The colour of rosé wines depends not only on the grape variety utilised, but also on other factors, such as the maceration time during winemaking. Since the same rosé must was used for this study, the variation in total anthocyanin content could be due to the precipitation of colouring matter, and, therefore, $H$. vineae was able to maintain a higher amount of stable pigments.

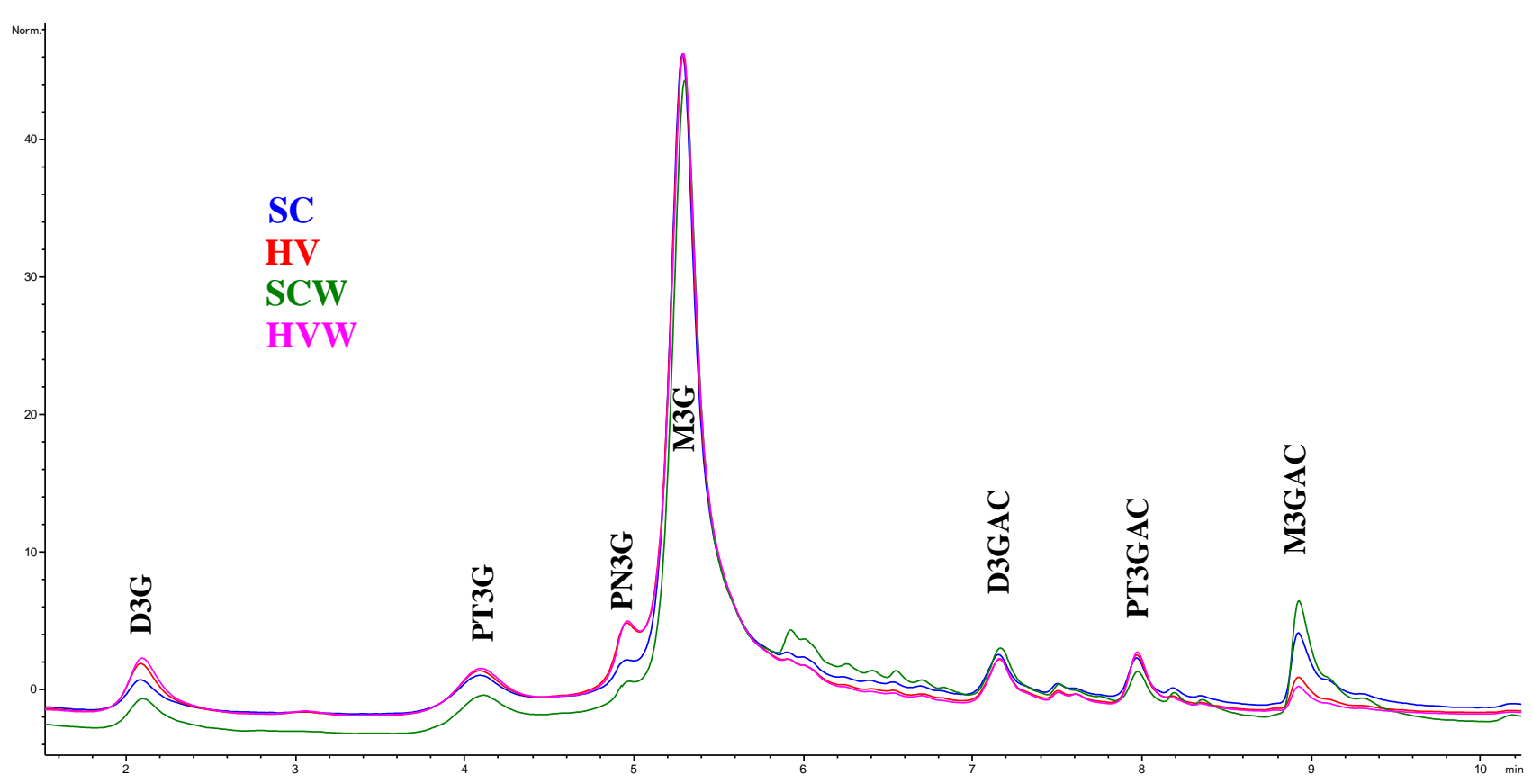

Figure 2. Chromatograms for anthocyanin identification by HPLC-DAD. SC (fermentations with S. cerevisiae in stainless steel barrels); HV (fermentations with $H$. vineae in stainless steel barrels); SCW (fermentations with $S$. cerevisiae in oak barrels); HVW (fermentations with H. vineae in oak barrels).

Table 2. Anthocyanins content (mg/L) measured by HPLC-DAD.

\begin{tabular}{|c|c|c|c|c|c|c|c|c|}
\hline & $\begin{array}{c}\text { Delphinidin } \\
\text { 3-O- } \\
\text { Glucoside } \\
\text { (D3G) (mg/L) }\end{array}$ & $\begin{array}{l}\text { Petunidin 3- } \\
\text { O-Glucoside } \\
\text { (PT3G) } \\
\text { (mg/L) }\end{array}$ & $\begin{array}{l}\text { Peonidin } \\
\text { 3-O- } \\
\text { Glucoside } \\
\text { (PN3G) } \\
\text { (mg/L) }\end{array}$ & $\begin{array}{c}\text { Malvidin } \\
\text { 3-O- } \\
\text { Glucoside } \\
\text { (M3G) (mg/L) }\end{array}$ & $\begin{array}{l}\text { Delphinidin } \\
\text { 3-O-(6"-O- } \\
\text { Acetyl) } \\
\text { Glucoside } \\
\text { (D3GAC) } \\
\text { (mg/L) }\end{array}$ & $\begin{array}{l}\text { Petunidin } \\
\text { 3-O-(6"-O- } \\
\text { Acetyl) } \\
\text { Glucoside } \\
\text { (PT3GAC) } \\
\text { (mg/L) }\end{array}$ & $\begin{array}{l}\text { Malvidin } \\
\text { 3-O-(6"-O- } \\
\text { Acetyl) } \\
\text { Glucoside } \\
\text { (M3GAC) } \\
\text { (mg/L) }\end{array}$ & $\begin{array}{c}\text { Total } \\
\text { Anthocyanin } \\
\text { Content } \\
(\mathrm{mg} / \mathrm{L})\end{array}$ \\
\hline SC & $3.78 \pm 0.20^{a}$ & $4.28 \pm 0.22^{b}$ & $3.61 \pm 0.10^{a}$ & $31.69 \pm 1.27^{b}$ & $4.06 \pm 0.07^{b}$ & $3.82 \pm 0.07^{b}$ & $4.64 \pm 0.02^{c}$ & $55.87 \pm 1.69^{b}$ \\
\hline $\mathrm{HV}$ & $4.79 \pm 0.32^{b}$ & $4.96 \pm 0.13^{c}$ & $4.84 \pm 0.40^{b}$ & $35.98 \pm 0.27^{c}$ & $4.25 \pm 0.03^{c}$ & $4.24 \pm 0.00^{\mathrm{c}}$ & $3.63 \pm 0.09^{b}$ & $62.70 \pm 0.40^{c}$ \\
\hline SCW & $3.63 \pm 0.16^{a}$ & $3.80 \pm 0.02^{a}$ & $3.33 \pm 0.15^{\mathrm{a}}$ & $23.60 \pm 2.35^{\mathrm{a}}$ & $3.78 \pm 0.02^{\mathrm{a}}$ & $3.39 \pm 0.11^{a}$ & $4.76 \pm 0.05^{\mathrm{c}}$ & $46.29 \pm 2.71^{a}$ \\
\hline HVW & $5.54 \pm 0.15^{c}$ & $4.98 \pm 0.03^{c}$ & $5.16 \pm 0.14^{b}$ & $38.56 \pm 0.42^{d}$ & $4.41 \pm 0.02^{\mathrm{d}}$ & $4.46 \pm 0.02^{\mathrm{d}}$ & $3.50 \pm 0.03^{a}$ & $66.61 \pm 0.60^{d}$ \\
\hline
\end{tabular}

SC (fermentations with S. cerevisiae in stainless steel barrels); HV (fermentations with H. vineae in stainless steel barrels); SCW (fermentations with S. cerevisiae in oak barrels); HVW (fermentations with H. vineae in oak barrels). Values in the same column with the same letter are not significantly different $(p<0.05)$.

Malvidin 3-O-glucoside (M3G) is the main pigment, and, therefore, followed the same trend as the total anthocyanins content obtaining values up to $38.56 \mathrm{mg} / \mathrm{L}$ in $\mathrm{HVW}$ wines. However, when this compound is acylated (M3GAC), the highest concentrations are found in the samples fermented by $S$. cerevisiae. Regarding the other pigments identified, all samples fermented by $H$. vineae resulted in significantly higher concentrations of anthocyanins, and this matched with the colour measurements (Figure 1a). In this respect, the higher concentrations of acylated pigments, except M3GAC, in HV and HVW wines are 
noteworthy. These compounds are bluer than the non-acylated ones, and this was reflected in the $b^{*}$ value of the CIELab coordinates (Figure 1a). The variations in the concentration of these acylated pigments may also be due to the fermentation kinetics of the two yeasts studied. The rate of ethanol formation in the medium can influence the solubility of the pigments; slower fermentations usually result in a higher amount of colouring matter in the solution.

\subsection{Polysaccharides Released during the Fermentation Process}

The polysaccharide content identified in the studied wines can be seen in Figure 3a. The comparison of the different chromatograms by HPLC-DAD that were obtained in the fermentations can also be observed in Figure $3 \mathrm{~b}$. The double peak corresponds to the wine polysaccharides in a retention time of $6.5-10 \mathrm{~min}$. It is interesting to note that the different yeast strains gave rise to different peak shapes without appreciable differences, depending on the material of the barrel in which they were fermented.
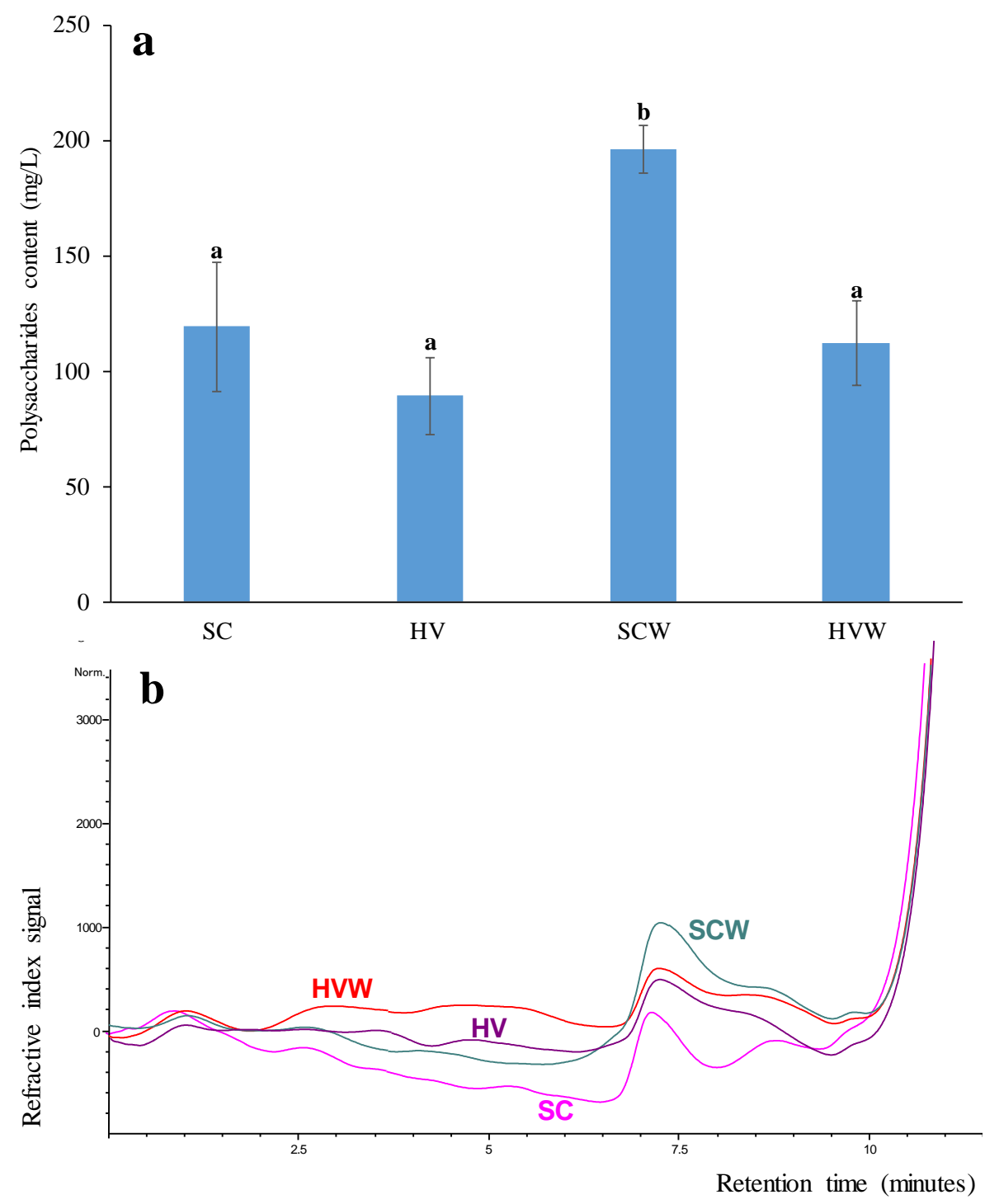

Figure 3. Polysaccharides (mg/L) (a) and chromatogram (b) measured by molecular exclusion liquid chromatography-refractive index detection (LC-RID). SC (fermentations with S. cerevisiae in stainless steel barrels); HV (fermentations with $H$. vineae in stainless steel barrels); SCW (fermentations with $S$. cerevisiae in oak barrels); HVW (fermentations with $H$. vineae in oak barrels). Bars with the same letter are not significantly different $(p<0.05)$. 
In relation to the amount of polysaccharides identified, it is important to note that these polysaccharide values correspond to the sum of both polysaccharides from the grape and yeast cell wall. The grape polysaccharides include polysaccharides, rich in arabinose, and galactose and polysaccharides, rich in rhamnogalacturonans, which both come from the pectocellulosic cell walls of the grape berries. The cell wall polysaccharides include the mannoproteins, and these compounds are released by yeasts during fermentation and the lees ageing process [30]. Wines fermented in stainless steel barrels showed a polysaccharide content between 89 and $119 \mathrm{mg} / \mathrm{L}$, with no significant differences between the different yeasts studied. However, wines fermented by S. cerevisiae in oak barrels showed a higher concentration of these compounds of around $195 \mathrm{mg} / \mathrm{L}$. Therefore, fermentation tank material may have an influence on the release of these compounds from yeast cell walls. As these differences were not found in stainless steel tanks, we cannot be sure that there is a higher polysaccharide release by $S$. cerevisiae in all fermentation conditions. Other authors have found higher amounts of polysaccharides (425-605 mg/L) after HPLC-RI analysis of red wines [31]. It is possible that these differences are due to the fact that maceration of red wines with grape skins resulted in a greater transfer of polysaccharides from the pectocellulosic cell walls of grape berries. Finally, it is interesting to note that as these are young wines, hence the contribution of polysaccharides yielded by the yeast cell lysis process is low. Since the process of cell lysis is slow, in previous investigations the release of these compounds in model medium was between 12-13 mg/L after 4.5 months of lees ageing assisted with ultrasounds [32]. Similarly, other authors identified amounts of $16-22 \mathrm{mg} / \mathrm{L}$ in model mediums after 7 months of ageing [33].

\subsection{Volatile Compounds Produced by Fermentation}

Table 3 shows aroma compounds produced during fermentation, measured by GC-FID. The wines fermented by S. cerevisiae in stainless steel barrels (SC) resulted in a significantly higher concentration of total volatiles than other treatments. In relation to the concentration of acetaldehyde, higher amounts were found in the wines aged in oak barrels (SCW and HVW), but without significant differences depending on the yeast strain identified. However, HVW samples resulted in lower diacetyl concentrations than the other wines. There were no significant differences in acetoin formation for all of the wines studied. Finally, 2,3-butanediol content was $536 \mathrm{mg} / \mathrm{L}$ for SC, a higher concentration than the amount identified in the other samples.

Table 3. Volatile compounds produced by fermentation (mg/L), measured by GC-FID. Mean \pm standard deviation of three replicates.

\begin{tabular}{|c|c|c|c|c|}
\hline Compound & SC & HV & SCW & HVW \\
\hline Acetaldehyde & $63.25 \pm 4.63^{\mathrm{a}}$ & $70.23 \pm 2.76^{a, b}$ & $74.75 \pm 0.65^{b, c}$ & $79.08 \pm 6.57^{c}$ \\
\hline Methanol & $26.64 \pm 0.84^{b}$ & $27.21 \pm 2.07^{b}$ & $22.84 \pm 2.86^{\mathrm{a}}$ & $25.31 \pm 0.68^{a, b}$ \\
\hline Diacetyl & $1.55 \pm 0.07^{\mathrm{b}}$ & $1.60 \pm 0.12^{b}$ & $1.56 \pm 0.01^{b}$ & $0.49 \pm 0.84^{\mathrm{a}}$ \\
\hline Acetoin & $5.50 \pm 0.05^{\mathrm{a}}$ & $6.46 \pm 1.32^{\mathrm{a}}$ & $5.74 \pm 1.66^{\mathrm{a}}$ & $5.70 \pm 0.40^{\mathrm{a}}$ \\
\hline 2,3-butanediol & $536.22 \pm 80.81^{b}$ & $381.94 \pm 41.65^{\mathrm{a}}$ & $360.03 \pm 13.82^{a}$ & $394.49 \pm 89.51^{\mathrm{a}}$ \\
\hline Isobutanol & $21.05 \pm 0.85^{b}$ & $17.73 \pm 0.40^{\mathrm{a}}$ & $26.24 \pm 1.04^{c}$ & $18.21 \pm 0.40^{\mathrm{a}}$ \\
\hline 1-propanol & $24.23 \pm 0.63^{b}$ & $20.23 \pm 1.59^{a}$ & $24.41 \pm 0.49^{b}$ & $20.22 \pm 1.67^{\mathrm{a}}$ \\
\hline 2-methyl-1-butanol & $24.17 \pm 0.57^{b, c}$ & $19.44 \pm 1.07^{\mathrm{a}}$ & $25.46 \pm 1.47^{c}$ & $22.58 \pm 0.91^{b}$ \\
\hline 3-methyl-1-butanol & $120.25 \pm 0.72^{c}$ & $93.13 \pm 4.75^{\mathrm{a}}$ & $125.40 \pm 2.97^{c}$ & $108.64 \pm 1.34^{b}$ \\
\hline Hexanol & $4.46 \pm 0.18^{b}$ & $4.17 \pm 0.22^{\mathrm{a}, \mathrm{b}}$ & $4.10 \pm 0.29^{\mathrm{a}, \mathrm{b}}$ & $3.86 \pm 0.03^{\mathrm{a}}$ \\
\hline 2-phenyl-ethanol & $16.46 \pm 0.96^{\mathrm{a}}$ & $15.21 \pm 0.27^{\mathrm{a}}$ & $17.08 \pm 1.63^{a}$ & $16.16 \pm 1.47^{a}$ \\
\hline$\sum$ Higher alcohols & $210.61 \pm 1.29^{c}$ & $169.91 \pm 7.56^{\mathrm{a}}$ & $222.69 \pm 4.97^{\mathrm{d}}$ & $189.67 \pm 4.80^{b}$ \\
\hline Ethyl lactate & $15.25 \pm 1.60^{b}$ & $14.50 \pm 3.75^{\mathrm{a}, \mathrm{b}}$ & $10.11 \pm 0.83^{a}$ & $15.08 \pm 3.19^{b}$ \\
\hline Ethyl acetate & $70.96 \pm 4.09^{b}$ & $57.55 \pm 4.62^{\mathrm{a}}$ & $85.08 \pm 2.99^{c}$ & $63.30 \pm 3.20^{\mathrm{a}}$ \\
\hline Isoamyl acetate & $4.63 \pm 0.11^{\mathrm{a}, \mathrm{b}}$ & $4.52 \pm 0.37^{\mathrm{a}}$ & $5.08 \pm 0.22^{b}$ & $4.89 \pm 0.39^{\mathrm{a}, \mathrm{b}}$ \\
\hline 2-phenylethyl acetate & $9.28 \pm 1.63^{b}$ & $15.38 \pm 1.22^{c}$ & $6.66 \pm 0.60^{\mathrm{a}}$ & $7.35 \pm 0.40^{\mathrm{a}, \mathrm{b}}$ \\
\hline$\sum$ Esters & $100.12 \pm 6.34^{\mathrm{a}, \mathrm{b}}$ & $93.45 \pm 5.37^{\mathrm{a}}$ & $106.93 \pm 3.16^{b}$ & $90.62 \pm 5.76^{\mathrm{a}}$ \\
\hline$\sum$ Total volatiles & $943.90 \pm 78.80^{b}$ & $750.80 \pm 28.39^{a}$ & $794.54 \pm 22.04^{a}$ & $785.37 \pm 100.17^{\mathrm{a}}$ \\
\hline
\end{tabular}

SC (fermentations with S. cerevisiae in stainless steel barrels); HV (fermentations with H. vineae in stainless steel barrels); SCW (fermentations with S. cerevisiae in oak barrels); HVW (fermentations with H. vineae in oak barrels). Values in the same row with the same letter are not significantly different $(p<0.05)$. 
The alcohols generated during $S$. cerevisiae fermentation were higher in all cases (SC and SCW), irrespective of the barrel material in which the wines were fermented. None of the fermentations exceeded an alcohol content of more than $400 \mathrm{mg} / \mathrm{L}$, which is considered to negatively affect the wine's quality [34]. In particular, this increased concentration in SC and SCW fermentations was intensified for compounds, such as 2-methyl-1-butanol and 3-methyl-1-butanol. These are the most important higher alcohols, in which their aroma was identified by a pungent odour with a perception threshold of $40 \mathrm{mg} / \mathrm{L}$ [35]. The only higher alcohol that contributes positively to the aroma of wine is 2-phenyl-ethanol, which has the olfactory descriptor of rose petals [9]. The obtained concentrations of this compound were between 16.46 and $17.08 \mathrm{mg} / \mathrm{L}$, with no significant differences between the yeast treatments studied. We obtained similar results when comparing both species in fermentations of Albillo grape variety, but with less concentrations of 2-phenyl-ethanol (around $9.6 \mathrm{mg} / \mathrm{L}$ ) [12]. However, other authors have observed even higher yields of this compound when fermenting $H$. vineae sequentially with $S$. cerevisiae, compared to pure fermentations of $S$. cerevisiae and other non-Saccharomyces yeasts [36].

Volatile esters are an important group of aromatic compounds, and are considered to be the main source of the fruity aroma of wines [37]. The most abundant ester in wine is ethyl acetate; the identified amounts of this compound were significantly higher in $S$. cerevisiae fermentations compared to $H$. vineae, with values between 70 and $85 \mathrm{mg} / \mathrm{L}$. It is interesting to note that ethyl acetate concentrations below $80 \mathrm{mg} / \mathrm{L}$ provide a positive organoleptic perception [38]. Another important ester is 2-phenylethyl acetate, as this compound has a strong aromatic power and is associated with fruity, floral and honey aromas [11]. Previous studies have linked H. vineae yeast to an increase in 2-phenylethyl acetate content [39]. In the present work, an increase in the concentration of this compound was also observed in $H$. vineae wines, particularly when fermentation was carried out in stainless steel barrels (HV). In this case, there was an increase of up to $65 \%$ compared to fermentations with $S$. cerevisiae.

\subsection{Volatile Compounds Measured by GC-MS}

Different families of compounds were identified by GC-MS. As they are mainly oakderived compounds, only wines fermented in oak barrels were analysed. The first group of compounds is the sum of norisoprenoids and terpenes alcohols. $\beta$-ionone was the only norisoprenoid identified. This is an odorant compound that is generated from $\beta$-carotene by thermal degradation, or by photo-oxygenation. $\beta$-ionone is a compound widely used in perfumery for its violet odour [40]. S. cerevisiae fermentations showed values around $30 \mu \mathrm{g} / \mathrm{L}$, which is about twice as high as the $H$. vineae samples. The average amount of $\beta$-ionone in wines varies considerably, from a few micrograms per litre to more than $60 \mu \mathrm{g} / \mathrm{L}$ [41]. However, based on the sum of norisoprenoids and terpene alcohols, the highest amounts were identified in wines fermented by $H$. vineae (Figure 4 ). This is because significantly higher amounts of the terpene linalool were identified in $H$. vineae, with values around $1000 \mu \mathrm{g} / \mathrm{L}$ which is about twice higher compared to $S$. cerevisiae wines. The monoterpene linalool is important for its aromatic contribution in aromatic white grape varieties (about 1-4 mg/L), but other grape varieties with lower concentrations, such as Chardonnay might also have a floral impact due to the low sensory threshold of linalool at about $10 \mu \mathrm{g} / \mathrm{L}$ [42].

Regarding the compounds extracted from oak wood, the volatile phenols include eugenol and guaiacol. Both are obtained by the breakdown of lignin during the cooperage toasting process. Guaiacol is the compound responsible for the burnt and smoky aromas of aged wines, and eugenol provides spicy and smoky aromas [43]. The concentrations of total volatile phenols in SCW samples were higher than in HV samples, but without significant differences between them. Other aroma groups analysed were the furanic compounds, which include furfural, 5-methyl furfural and furfuryl alcohol. These compounds are derived from the degradation of cellulose and hemicellulose monosaccharides [44]. Concentrations between 350 and $400 \mu \mathrm{g} / \mathrm{L}$ were obtained with no significant differences 
between the yeast strains used. These are not higher values compared to those obtained by other authors after wine ageing in oak barrels [45], with an average value of 4500 and $4700 \mu \mathrm{g} / \mathrm{L}$ of furfural in French and American oak barrels, respectively. No significant differences were identified in the concentration of lactones transferred from the barrel during the fermentation. Values obtained were between 40 and $50 \mu \mathrm{g} / \mathrm{L}$ for both yeasts. These values did not have a significant aromatic impact on the wine as the perception threshold for cis-isomer is $92 \mu \mathrm{g} / \mathrm{L}$ [46]. Finally, small amounts of ethylphenols were found, with no significant differences between the wines and all being below the threshold of perception of this compound, $140 \mu \mathrm{g} / \mathrm{L}$ for 4-ethylguaiacol, according to [47].

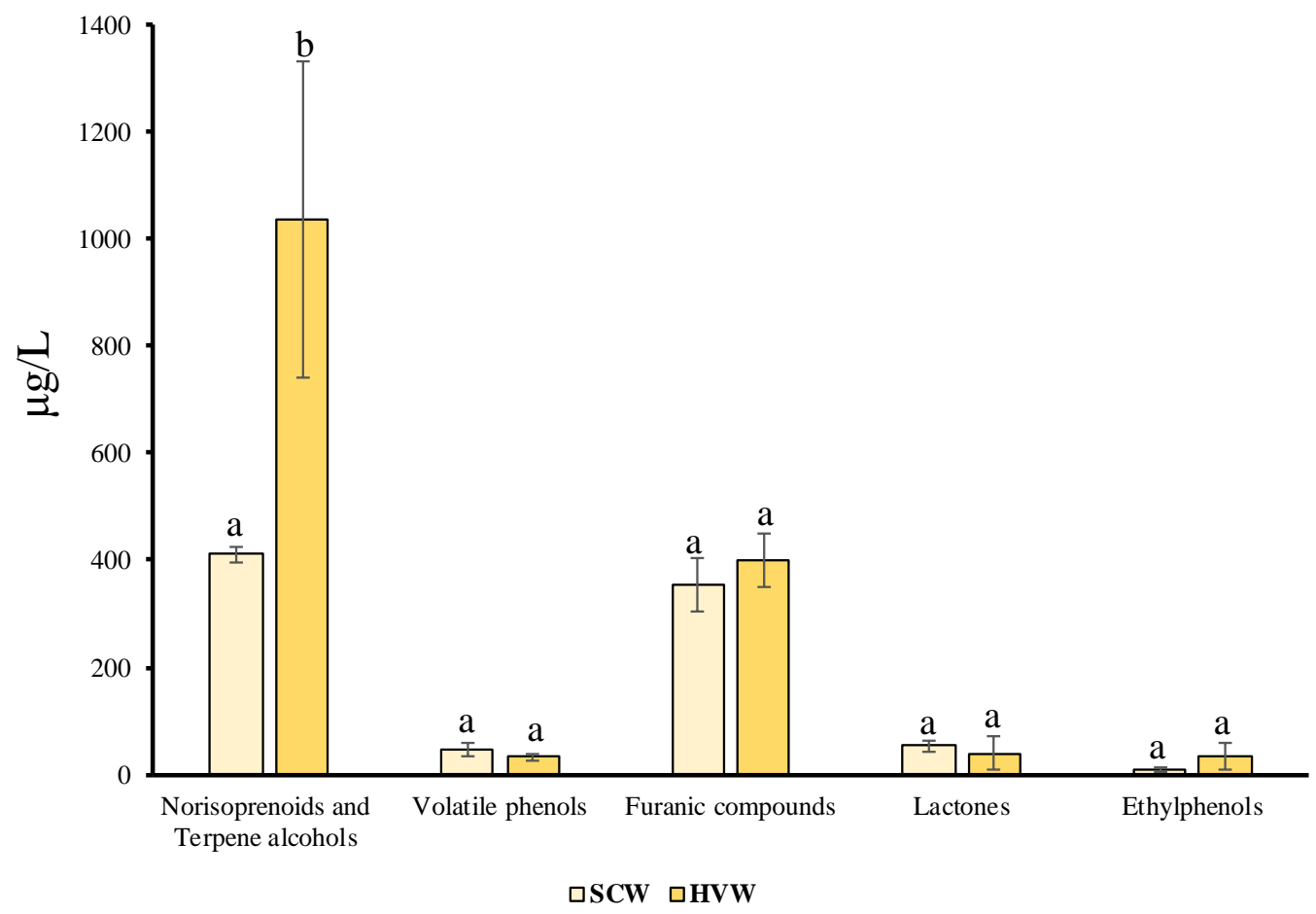

Figure 4. Volatile compounds measured by GC-MS. SCW (fermentations with S. cerevisiae in oak barrels); HVW (fermentations with $H$. vineae in oak barrels). Mean \pm standard deviation of two replicates. Bars with the same letter are not significantly different $(p<0.05)$.

\subsection{Sensory Analysis}

The sensory analysis of the wines studied showed that there were no significant differences in the colour intensity parameter (Figure 5). However, the tasters identified a clear increase in tonality in S. cerevisiae wines. These results are in agreement with spectrophotometric colour measurements, both in tonality and in the CIELab coordinates including the yellow component (Figure 1). These differences may be due to the higher concentrations of acylated anthocyanins identified in H. vineae wines (Figure 2).

In relation to aromatic parameters, the tasters did not identify differences in the aromatic intensity of the wines studied. However, $H$. vineae wines were scored higher on the floral parameter. These scores are possibly due to the higher 2-phenylethyl acetate concentrations (Table 3). In the same way, the high linalool content could influence this parameter too (Figure 4). Tasters described H. vineae wines as fruitier than S. cerevisiae wines, and these results are in the agreement with the higher content of 2-phenylethyl acetate. The wood character was perfectly identified in samples fermented in oak barrels. 


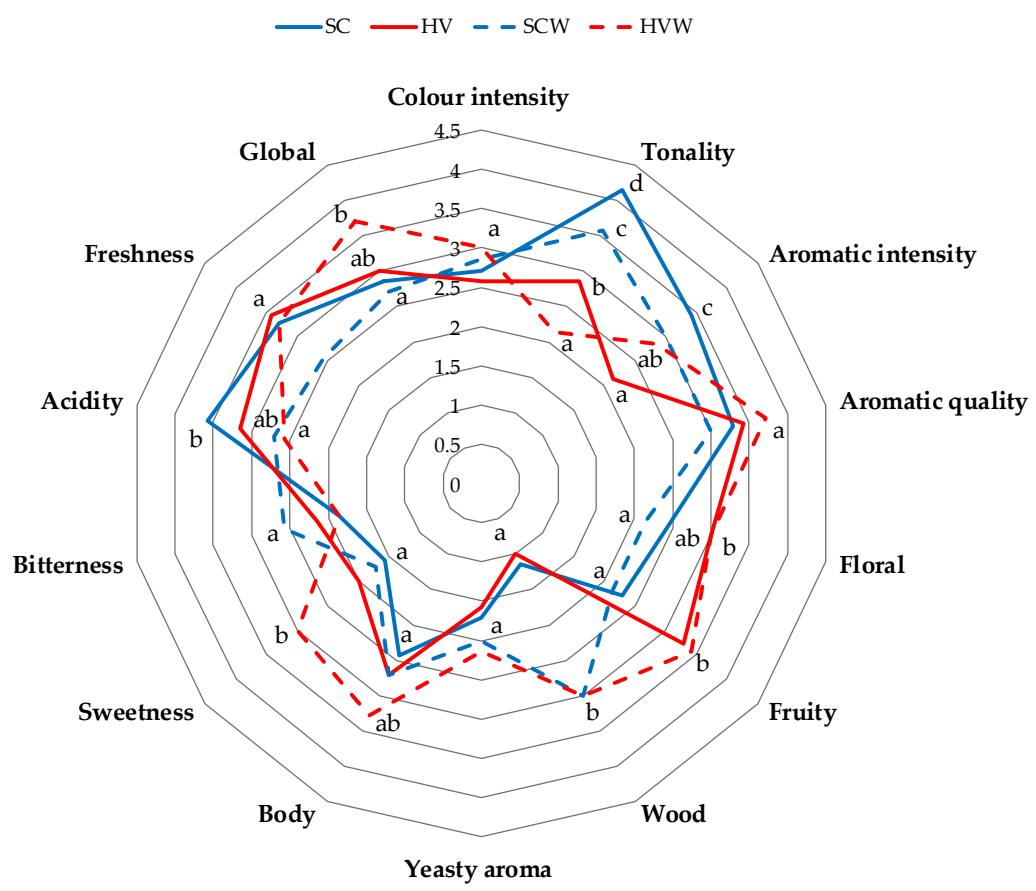

Figure 5. Spider plot showing sensory analysis by eight trained tasters. SC (fermentations with $S$. cerevisiae in stainless steel barrels); HV (fermentations with $H$. vineae in stainless steel barrels); SCW (fermentations with S. cerevisiae in oak barrels); HVW (fermentations with $H$. vineae in oak barrels). Means in the same axis with the same letter are not significantly different $(p<0.05)$.

No major differences in mouthfeel were identified, with the exception of the HVW wines which were rated as sweeter than the rest, and SC wines were found to be more acidic than HVW wines. Finally, the global perception was higher in HVW wines.

\section{Conclusions}

The use of $H$. vineae in rosé winemaking resulted in wines with similar general oenological parameters to those obtained with a commercial S. cerevisiae. Wines fermented with $H$. vineae preserved a higher amount of total pigments, and this is reflected by spectrophotometric analysis where $H$. vineae wines showed more reddish and less yellowish tones. These colour differences were visible to the naked eye. There were no clear results on the yeast dependence on the amount of polysaccharides obtained. In terms of the aromatic profile of the wines obtained, significant increases in the 2-phenylethyl acetate compound were identified with $H$. vineae treatments, which were particularly noticeable in stainless steel barrel fermentations. In addition, $H$. vineae produced wines with a lower content of both higher alcohols and ethyl acetate. Higher concentrations of linalool were also identified in $H$. vineae wines, which might also contribute to floral note characteristics with concentrations above the sensory threshold.

$H$. vineae is a yeast species with an interesting application for the production of Tempranillo and Albillo rosé wines. It is able to produce a good aromatic profile, by increasing the amount of sensory desirable compounds. In addition, it is able to hold a higher amount of pigments, resulting in more attractive colours.

Author Contributions: J.M.D.F. performed the analysis and drafted the manuscript; I.L. revised and corrected the manuscript; C.E. revised and corrected the manuscript; F.C. revised and corrected the manuscript; C.G. revised and corrected the manuscript; R.C. performed the fermentations assays in the winery; and A.M. undertook the study's conceptualisation, coordinated the investigation and revised the manuscript. All authors have read and agreed to the published version of the manuscript. 
Funding: This research was funded by Projects FPA190000TEC2407-Oenological evaluation of one selected strain of Hanseniaspora vineae and ANII, ALI_2_2019_1_155314 H. vineae Project FQ—Lage y Cia-Uruguay.

Acknowledgments: Thanks to Bodegas Comenge for making the rosé wines and for the grapes from their vineyards and winery facilities.

Conflicts of Interest: The authors declare no conflict of interest.

\section{Appendix A}

The fermentation kinetics of the different rosé wines studied are shown in Figure A1. During the first days of fermentation, a higher density loss was identified in H. vineae samples than in S. cerevisiae samples. The stainless steel barrels finished the fermentation after 33 days. However, the oak barrels completed fermentation more quickly, as no differences in density were detected after 22 days. This fact was observed for both yeast species; therefore, the fermentation tank material seems to have a significant influence on the fermentation kinetics.

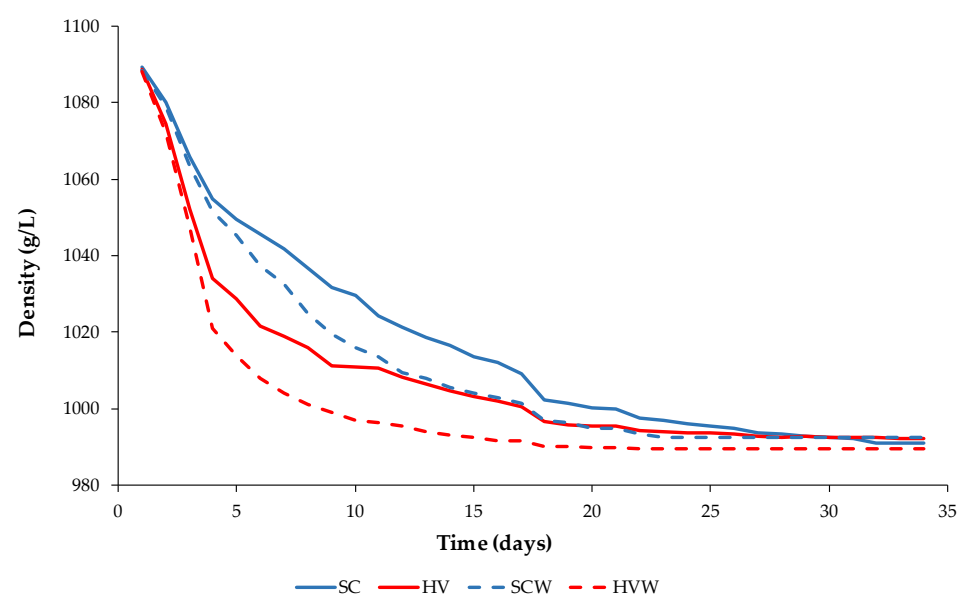

Figure A1. Fermentation kinetics of studied yeast strains. SC (fermentations with S. cerevisiae in stainless steel barrels); HV (fermentations with H. vineae in stainless steel barrels); SCW (fermentations with $S$. cerevisiae in oak barrels); HVW (fermentations with $H$. vineae in oak barrels).

\section{References}

1. Salinas, M.R.; Garijo, J.; Pardo, F.; Zalacain, A.; Alonso, G.L. Influence of prefermentative maceration temperature on the colour and the phenolic and volatile composition of rosé wines. J. Sci. Food Agric. 2005, 85, 1527-1536. [CrossRef]

2. Fraile, P.; Garrido, J.; Ancín, C. Influence of a Saccharomyces cerevisiae selected strain in the volatile composition of rose wines. Evolution during fermentation. J. Agric. Food Chem. 2000, 48, 1789-1798. [CrossRef]

3. Morata, A.; Escott, C.; Bañuelos, M.A.; Loira, I.; Del Fresno, J.M.; González, C.; Suárez-lepe, J.A. Contribution of non-Saccharomyces yeasts to wine freshness. A review. Biomolecules 2020, 10, 34. [CrossRef]

4. Prakitchaiwattana, C.J.; Fleet, G.H.; Heard, G.M. Application and evaluation of denaturing gradient gel electrophoresis to analyse the yeast ecology of wine grapes. FEMS Yeast Res. 2004, 4, 865-877. [CrossRef] [PubMed]

5. Martínez, M.J.V.; Valera, M.J.; Medina, K.; Boido, E.; Carrau, F. Oenological Impact of the Hanseniaspora/Kloeckera Yeast Genus on Wines-A Review. Fermentation 2018, 4, 76. [CrossRef]

6. Heard, G.M.; Fleet, G.H. The effects of temperature and $\mathrm{pH}$ on the growth of yeast species during the fermentation of grape juice. J. Appl. Bacteriol. 1988, 65, 23-28. [CrossRef]

7. Medina, K.; Boido, E.; Fariña, L.; Gioia, O.; Gomez, M.; Barquet, M.; Gaggero, C.; Dellacassa, E.; Carrau, F. Increased flavour diversity of Chardonnay wines by spontaneous fermentation and co-fermentation with Hanseniaspora vineae. Food Chem. 2013, 141, 2513-2521. [CrossRef]

8. Viana, F.; Belloch, C.; Vallés, S.; Manzanares, P. Monitoring a mixed starter of Hanseniaspora vineae-Saccharomyces cerevisiae in natural must: Impact on 2-phenylethyl acetate production. Int. J. Food Microbiol. 2011, 151, 235-240. [CrossRef]

9. Swiegers, J.H.; Bartowsky, E.; Henschke, P.; Pretorius, I. Yeast and bacterial modulation of wine aroma and flavour. Aust. J. Grape Wine Res. 2005, 11, 139-173. [CrossRef] 
10. Cordente, A.G.; Solomon, M.; Schulkin, A.; Francis, I.L.; Barker, A.; Borneman, A.R.; Curtin, C.D. Novel wine yeast with ARO4 and TYR1 mutations that overproduce 'floral' aroma compounds 2-phenylethanol and 2-phenylethyl acetate. Appl. Microbiol. Biotechnol. 2018, 102, 5977-5988. [CrossRef]

11. Lleixà, J.; Martin, V.; Portillo, M.C.; Carrau, F.; Beltran, G.; Mas, A. Comparison of Fermentation and Wines Produced by Inoculation of Hanseniaspora vineae and Saccharomyces cerevisiae. Front. Microbiol. 2016, 7, 338. [CrossRef] [PubMed]

12. Del Fresno, J.M.; Escott, C.; Loira, I.; Herbert-Pucheta, J.E.; Schneider, R.; Carrau, F.; Cuerda, R.; Morata, A. Impact of Hanseniaspora vineae in alcoholic fermentation and ageing on lees of high-quality whitewine. Fermentation 2020, 6, 66. [CrossRef]

13. Del Fresno, J.; Escott, C.; Loira, I.; Carrau, F.; Cuerda, R.; Schneider, R.; Bañuelos, M.; González, C.; Suárez-Lepe, J.; Morata, A. The Impact of Hanseniaspora vineae Fermentation and Ageing on Lees on the Terpenic Aromatic Profile of White Wines of the Albillo Variety. Int. J. Mol. Sci. 2021, 22, 2195. [CrossRef] [PubMed]

14. Ramos, M.C.; Jones, G.V.; Yuste, J. Spatial and temporal variability of cv. Tempranillo phenology and grape quality within the Ribera del Duero DO (Spain) and relationships with climate. Int. J. Biometeorol. 2015, 59, 1849-1860. [CrossRef]

15. Variedades de uva I Ribera del Duero. Available online: https://www.riberadelduero.es/la-do-ribera-del-duero/variedades-deuva (accessed on 18 June 2021).

16. Escott, C.; Vaquero, C.; del Fresno, J.M.; Bañuelos, M.A.; Loira, I.; Han, S.-Y.; Bi, Y.; Morata, A.; Suárez-Lepe, J.A. Pulsed Light Effect in Red Grape Quality and Fermentation. Food Bioprocess Technol. 2017, 10, 1540-1547. [CrossRef]

17. Loira, I.; Vejarano, R.; Morata, A.; Ricardo-Da-Silva, J.M.; Laureano, O.; González, M.; Suárez-Lepe, J. Effect of Saccharomyces strains on the quality of red wines aged on lees. Food Chem. 2013, 139, 1044-1051. [CrossRef]

18. Abalos, D.; Vejarano, R.; Morata, A.; González, C.; Suárez-Lepe, J.A.; Vejarano-Mantilla, R.D. The use of furfural as a metabolic inhibitor for reducing the alcohol content of model wines. Eur. Food Res. Technol. 2011, 232, 663-669. [CrossRef]

19. Waterhouse, A.L.; Sacks, G.; Jeffery, D.W. Understanding Wine Chemistry; John Wiley \& Sons: Hoboken, NJ, USA, 2016. [CrossRef]

20. Zohre, D.; Erten, H. The influence of Kloeckera apiculata and Candida pulcherrima yeasts on wine fermentation. Process. Biochem. 2002, 38, 319-324. [CrossRef]

21. Comitini, F.; Ciani, M. The zymocidial activity of Tetrapisispora phaffii in the control of Hanseniaspora uvarum during the early stages of winemaking. Lett. Appl. Microbiol. 2010, 50, 50-56. [CrossRef]

22. Ciani, M.; Beco, L.; Comitini, F. Fermentation behaviour and metabolic interactions of multistarter wine yeast fermentations. Int. J. Food Microbiol. 2006, 108, 239-245. [CrossRef]

23. Gil-Muñoz, R.; Gómez-Plaza, E.; Martínez, A.; López-Roca, J. Evolution of the CIELAB and other spectrophotometric parameters during wine fermentation. Influence of some pre and postfermentative factors. Food Res. Int. 1997, 30, 699-705. [CrossRef]

24. Prez-Magario, S.; Gonzalez-SanJose, M.L. Prediction of red and rosé wine CIELab parameters from simple absorbance measurements. J. Sci. Food Agric. 2002, 82, 1319-1324. [CrossRef]

25. Bakker, J.; Bridle, P.; Timberlake, C.F. Tristimulus measurements (CIELAB 76) of port wine colour. Vitis 1986, 25, 67-78.

26. Almela, L.; Fernández-López, J.A.; Javaloy, S.; Fernhndez, J.A.; Lopez-Rota, M. Comparison between the tristimulus measurements $\mathrm{Yxy}$ and $\mathrm{L}^{*} \mathrm{a}^{*} \mathrm{~b}^{*}$ to evaluate the color of young red wines. Food Chem. 1995, 53, 321-327. [CrossRef]

27. Núñez, V.; Monagas, M.; Gomez-Cordovés, M.; Bartolomé, B. Vitis vinifera L. cv. Graciano grapes characterized by its anthocyanin profile. Postharvest Biol. Technol. 2004, 31, 69-79. [CrossRef]

28. Puértolas, E.; Saldaña, G.; Álvarez, I.; Raso, J. Experimental design approach for the evaluation of anthocyanin content of rosé wines obtained by pulsed electric fields. Influence of temperature and time of maceration. Food Chem. 2011, 126, 1482-1487. [CrossRef]

29. Stávek, J.; Papoušková, B.; Balik, J.; Bednar, P. Effect of Storage Conditions on Various Parameters of Colour and the Anthocyanin Profile of Rosé Wines. Int. J. Food Prop. 2012, 15, 1133-1147. [CrossRef]

30. Martínez-Lapuente, L.; Guadalupe, Z.; Ayestarán, B. Properties of Wine Polysaccharides. In Pectins-Extraction, Purification, Characterization and Applications, 1st ed.; IntechOpen: London, UK, 2020; Volume 1, pp. 1-21.

31. Guadalupe, Z.; Martínez-Pinilla, O.; Garrido, Á.; Carrillo, J.D.; Ayestarán, B. Quantitative determination of wine polysaccharides by gas chromatography-mass spectrometry (GC-MS) and size exclusion chromatography (SEC). Food Chem. 2012, 131, 367-374. [CrossRef]

32. Del Fresno, J.M.; Loira, I.; Morata, A.; González, C.; Suárez-Lepe, J.A.; Cuerda, R. Application of ultrasound to improve lees ageing processes in red wines. Food Chem. 2018, 261, 157-163. [CrossRef]

33. Palomero, F.; Morata, A.; Benito, S.; Gonzalez, M.; Suárez-Lepe, J. Conventional and enzyme-assisted autolysis during ageing over lees in red wines: Influence on the release of polysaccharides from yeast cell walls and on wine monomeric anthocyanin content. Food Chem. 2007, 105, 838-846. [CrossRef]

34. Rapp, A.; Versini, G. Influence of Nitrogen Compounds in Grapes on Aroma Compounds of Wines; Elsevier: Amsterdam, The Netherlands, 1995; pp. 1659-1694. [CrossRef]

35. Vilanova, M.; Martínez, C. First study of determination of aromatic compounds of red wine from Vitis vinifera cv. Castañal grown in Galicia (NW Spain). Eur. Food Res. Technol. 2006, 224, 431-436. [CrossRef]

36. Zhang, B.Q.; Shen, J.Y.; Duan, C.Q.; Yan, G.L. Use of indigenous Hanseniaspora vineae and Metschnikowia pulcherrima Cofermentation with Saccharomyces cerevisiae to improve the aroma diversity of Vidal blanc ice wine. Front. Microbiol. 2018, 9 , 2303. [CrossRef] [PubMed] 
37. Sumby, K.; Grbin, P.; Jiranek, V. Microbial modulation of aromatic esters in wine: Current knowledge and future prospects. Food Chem. 2010, 121, 1-16. [CrossRef]

38. Plata, C.; Millán, C.; Mauricio, J.; Ortega, J. Formation of ethyl acetate and isoamyl acetate by various species of wine yeasts. Food Microbiol. 2003, 20, 217-224. [CrossRef]

39. Martin, V.; Giorello, F.; Fariña, L.; Minteguiaga, M.; Salzman, V.; Boido, E.; Aguilar, P.S.; Gaggero, C.; Dellacassa, E.; Mas, A.; et al. De NovoSynthesis of Benzenoid Compounds by the Yeast Hanseniaspora vineae Increases the Flavor Diversity of Wines. J. Agric. Food Chem. 2016, 64, 4574-4583. [CrossRef]

40. Kotseridis, Y.; Baumes, R.L.; Bertrand, A.; Skouroumounis, G.K. Quantitative determination of $\beta$-ionone in red wines and grapes of Bordeaux using a stable isotope dilution assay. J. Chromatogr. A 1999, 848, 317-325. [CrossRef]

41. Langen, J.; Wegmann-Herr, P.; Schmarr, H.G. Quantitative determination of $\alpha$-ionone, $\beta$-ionone, and $\beta$-damascenone and enantio differentiation of $\alpha$-ionone in wine for authenticity control using multidimensional gas chromatography with tandem mass spectrometric detection. Anal. Bioanal. Chem. 2016, 408, 6483-6496. [CrossRef] [PubMed]

42. Mateo, J.; Jiménez, M. Monoterpenes in grape juice and wines. J. Chromatogr. A 2000, 881, 557-567. [CrossRef]

43. Arapitsas, P.; Antonopoulos, A.; Stefanou, E.; Dourtoglou, V. Artificial aging of wines using oak chips. Food Chem. 2004, 86, 563-570. [CrossRef]

44. Garcia, R.; Soares, B.; Dias, C.B.; Freitas, A.M.C.; Cabrita, M.J. Phenolic and furanic compounds of Portuguese chestnut and French, American and Portuguese oak wood chips. Eur. Food Res. Technol. 2012, 235, 457-467. [CrossRef]

45. Towey, J.P.; Waterhouse, A.L. The Extraction of Volatile Compounds From French and American Oak Barrels in Chardonnay During Three Successive Vintages. Am. J. Enol. Vitic 1996, 47, 163-172.

46. Pérez-Prieto, L.J.; López-Roca, J.M.; Martínez-Cutillas, A.; Pardo Mínguez, F.; Gómez-Plaza, E. Maturing Wines in Oak Barrels. Effects of Origin, Volume, and Age of the Barrel on the Wine Volatile Composition. J. Agric. Food Chem. 2002, 50, 3272-3276. [CrossRef] [PubMed]

47. Chatonnet, P.; Dubourdie, D.; Boidron, J.-N.; Pons, M. The origin of ethylphenols in wines. J. Sci. Food Agric. 1992, 60, 165-178. [CrossRef] 